\title{
Towards Your Parents' Social Network Platform - A User Interface For the Age of Retirement
}

\author{
Friederike Boll \\ University of Applied Sciences \\ Neu-Ulm \\ Friederike.Boll@student.hs-neu- \\ ulm.de
}

\author{
Philipp Brune \\ University of Applied Sciences \\ Neu-Ulm \\ Philipp.Brune@,hs-neu-ulm.de
}

\author{
Heiko Gewald \\ University of Applied Sciences \\ Neu-Ulm \\ Heiko.Gewald@,hs-neu-ulm.de
}

\begin{abstract}
Most developed countries face an aging population, leading to various challenges due to this demographic change. On average, people turn from working life to retirement at the age of 65 . Related changes in their social environment threat their health, i.e. due to perceived social exclusion. Online Social Networks (OSN) may help them to overcome this problem. However, usability issues due to user interfaces (UI) perceived as inconsistent and confusing among other reasons prevent their adoption by the elderly so far. While UI design for elderly people has been discussed in the literature, few results exist on the 'younger' transition agers between 55-75. Therefore, in the present paper an approach for the design of UI for OSN specific for transition agers is presented and evaluated in a qualitative study. The results indicate that with specific, but not extraordinary UI adjustments, OSN could be made easily usable and more attractive for them.
\end{abstract}

\section{Introduction}

The aging population is a reality in most developed countries today. In Germany the amount of people over 65 is constantly rising. In $2011,20.4 \%$ of the population was more than 65 years old; by 2060, this figure will have risen to about 33\% [1]. The age of 65 is the point when people are described as "old" or "elderly" because this age marks the transition between working life and retirement. The shift in Germany's demographic profile poses significant challenges for the government, healthcare providers, and the society at large [2]. There are monetary costs, like providing healthcare services or other benefits to them. It is also necessary to keep the elderly functional, both in a cognitive and physical way, and active in society.

In addition to age and health-related problems, elderly people face a higher risk of suffering social exclu- sion [3]. Due to a lack of social participation and reduced social contacts. In particular, the transition from work life to retirement is associated with various risks for health and well-being, since people may lose roles that provide purpose and social contacts [4]. Typically, this transition happens at an age between 55 and 75 years, the so-called transition age.

The loss of purpose and social contacts due to retirement is specifically important for people who were very active at work and neglected their private social network. Additionally, family members today often live far away and the daily interaction with colleagues vanishes due to retirement. Emotional support from social networks can keep elderly people functionally capable [5] in particular since social integration is essential to satisfy basic human needs like being loved and the need to belong. Communication and exchange with other elderly people, friends, and especially family members can help to form a feeling of social connectedness and expand their social contacts [6]. The development of Online Social Networks (OSN) has further increased opportunities for social contact and enables users to interact and collaborate with others as part of an on-going social dialogue [7]. However, elderly people tend to not use OSN to stay in touch with family and friends. In 2014, only 9\% of all Facebook users were 55 years of age or older. Alternatives like Google + and Twitter only have about $7 \%$ of users who are more than 55 years old [8]. The reason for this is not only in the fact that they do not consider social networks necessary and useful, but also that only few OSN offer solutions to the special needs of elderly us [9].

Age-related changes have a significant impact on the computer usage of elderly people. These changes include declining vision, changes in psychomotoric coordination, reduced attention span, and impaired memory [10]. In addition, lack of computer skills lead to an uncomfortable feeling and anxiety towards computer usage in general [11]. These negative feelings towards using computer technology result in a general hesitation to user online services. In addition, the user interfaces (UI) 
of web pages and mobile devices are often too complex for elderly users, who often have not invested much time in learning the skills to use such systems [9]. The easiest solution would be to simplify the UI of these applications, thereby increasing the usability by reducing the complexity [10]. However, this approach also limits the functionality of applications and is only appropriate when only elderly users with little experience should use the application.

In addition, elderly users form a diverse group: some of them have little or no knowledge of how to use computers, mobile devices, or the internet: others have more experience due to computer-usage in their working lives or a general interest. The latter holds in particular true for the transition agers between 55 and 75 [12] . Thus, a more flexible approach is required for this age group, leading to UI for OSN that better suit the requirements of elderly people while not limiting the functionality of the application.

Therefore, in the present paper an approach for the design of typical structural elements of UI for OSN for users in the transition age (55-75 years) is presented, based on a prior qualitative study [12]. The approach is evaluated by a qualitative empirical study using a cognitive walkthrough by participants of the defined age group.

\section{Related Work}

Good design of web user interfaces is essential for the adoption of web services. First impressions are very powerful in a wide range of contexts [13] including studies on the perceptions of the appeal and usability [14], trust [15], and reliability of websites [16]. Lindgaard and Dudek [17] have shown that a website previously found to be visually very appealing was equally highly valued before and after a usability test in which over $50 \%$ of the participants were not able to complete one-half of the tasks successfully. However, the strong impact of the visual impression draws away the attention from usability problems. Therefore, the UI of a web service is of major importance because it has a great influence on the first impression of the users.

But especially elderly people often have problems using OSN and ICT since existing user interfaces are often too complex for them and do not meet their special requirements $[9,10,18,19]$. Older and younger adults differ significantly in their way of solving problems on websites [20]. Therefore, elderly people often have problems navigating successfully through web pages designed for younger users. However, elderly people form a diverse group [21]. Therefore, the UI design needs to take into account the needs of a heterogeneous group and cannot be designed to only solve the specific set of problems encountered by one individual user [10].
The design has to be simple and suitable for users that suffer from age-related changes [22]. Dias et al. [23] state that the success of any platform or web system is based on its usability features and improvements to make it comfortable to users. Therefore, the UI quality is always important for its usability [24]. Based on the general requirements of elderly users, 38 senior-friendly guidelines were developed [25].

Different models of user-friendly interfaces based on these guidelines were proposed, i.e. a social network application based on the Ambient Communication for Sense and Presence (AMCOSOP) standard [26], which offers users a secure network of family and health care services. A similar example is the health and wellbeing platform developed by Keijzer-Broers et al. [27], a multi-purpose platform where users can interact with each other, service providers can promote their products, and local service platforms are integrated. Another application especially designed for elderly users is the Senior Mail System [8], a mail application designed for older users.

While the transition age from work life to retirement between 55 and 75 is related to various problems with health and well-being [4], which might be addressed by appropriate online services, the IT-related skills of this age group significantly differ from those of older people [11].

However, most related studies and applications focus on elderly users that are about $65+$ years old, have little or no experience with the use of OSN and suffer from age-related changes. In addition, many of the existing studies are 5-12 years old, so the ICT experiences of elderly people as well as the platforms and technologies used are likely to have changed in the mean-time. Thus, the findings of these studies are not directly applicable to people in the transition age between 55 and 75 . This target group is expected to be extremely diverse with respect to ICT and OSN skills and usage behavior. The development of dedicated online services like OSN for people between 55 and 75 thus requires to better understand the specific needs and UI requirements of this age group.

Therefore, in the present paper the question is addressed, how the structural elements of the UI for an OSN application could be designed to incorporate in particular the requirements of users in the transition age between 55 and 75 years

\section{Design of Characteristic UI Elements}

The UI design elements proposed in the following was derived in the context of the implementation of an integrated online social and service network platform for people in the transition age as part of the FISnet 
Project $^{1}$ in southern Germany. This project aims to develop an individualized, cooperative service network in the region of Augsburg, Germany.The project focuses on the age group between 55 an 75 due to their high demographic importance in the next 20 years.

\subsection{Navigation}

The two traditional ways of positioning a menu bar are combined. The more classical approach is to position the menu bar at the upper left side, the more modern one is to use a horizontal navigation positioned above the content. Here, the primary main navigation bar is positioned horizontally above the content and below the logo and the buttons for login and logout. The menu bar splits the website in main sections and provides a quick overlook. The main navigation is directly available when the user enters the website and stays visible on any subpage.

The secondary navigation bar is positioned vertically on the left side of the website. This avoids dropdown menus in the main navigation bar. Figure 1 illustrates this layout of the primary and secondary navigation bars.

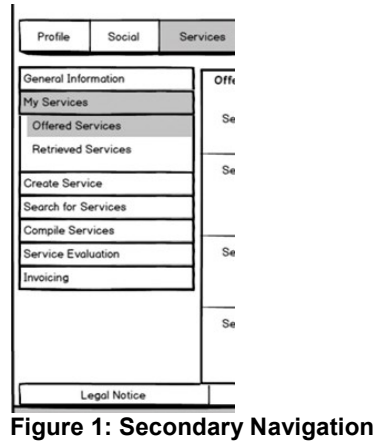

When the user chooses an item in the main navigation bar, the secondary navigation bar for this item appears on the left side and the user can see all menu items of the corresponding secondary menu. When selecting one item of the secondary menu, the third-level menu appears. The third-level menu level remains opened as the user stays on the same secondary menu level item. In this way the user is always aware of the general menu structure and the current navigation position In addition, drop-down menus are avoided which are considered confusing for inexperienced and elderly users because the menu disappears after making a selection [25].

Scrolling should be avoided [10,25] when designing a user interface for elderly users. Even since most users today use a mouse with a scroll wheel or a touch pad on their laptop and are familiar with scrolling, views that are very long and require a lot of scrolling can easily get confusing $[28,29]$. It is not possible to avoid scrolling completely, but here views that are too long aresplit into sections instead and register tabs are used to navigate between these sections as shown in Figure 2. Alternatively, fourth menu level could be established but this would lead to more difficulties when navigating the website.

\begin{tabular}{|l|l|l|l|l|l|}
\hline \multicolumn{1}{|c|}{ Fisnet } \\
\hline Profile & Social & Services & Messoges & Colendor & Contoct to FISnet \\
\hline News
\end{tabular}
Figure 2: Overall navigation structure of the UI, consisting of the vertical and horizontal primary and secondary navigation bars as well as register tabs for avoiding scrolling through lengthy content

The position of the currently displayed view within the navigation hierarchy is always indicated to the user by means of a breadcrumb navigation. Breadcrumbs are navigation elements that show the user the navigation path to the current page [30]. These breadcrumb elements frequently consist of hyperlinks for navigation. Here, breadcrumbs are implemented in a different way but with a similar function. Figure 2 also illustrates this implementation of breadcrumbs. The path that a user used to navigate to a certain page is marked in the navigation bar menus. In this way, it is possible for the user to always see the position of the selected page. The selected items in the primary and secondary navigation bars and the register tabs are marked by a specific color, respectively.

Buttons are a fundamental element of any UI. Especially for less experienced and elderly users they have to be big enough [25]. The optimum size depends on the importance of the button and its position [31]. The login button should be bigger than a button to confirm changes. In addition, the time required to move the cursor from the content area to the button determines its size. The longer it takes to move the button from the content area to the button, the larger the button should be. (Fitts's Law).

The proposed UI design incorporates buttons which are always big enough to be easily clickable and are clearly labeled textually with the action performed when the user clicks the button. Image buttons or icons can easily be misinterpreted by users who are not particularly experienced in using information technology [22]. Words describe functions more explicitly than icons and can be used more consistently. I.e., an icon used to close a window looks similar to the icon used to delete a file or an e-mail. This can be confusing for inexperienced

$1 \mathrm{http} / / / w w w . f i s n e t . i n f o /$ 
users. The words "close" and "delete" describe the meanings more clearly instead.

An important aspect of any navigation is consistency. It is important that users understand the basic menu structure and know what to expect from the individual parts of it. Here, the main navigation bar always stays in the same place, with the same menu items to choose from. The secondary navigation bar then adapts to the chosen item. The third level of the navigation only appears when the associated menu item of the secondary level is chosen. This behavior is the same for every menu item. In most cases buttons for actions related to the currently displayed content are displayed on the right side of the content area so that the user always knows where to find them.

Buttons which are used in wizards (i.e. for creating a profile or creating a new service offer) or in a confirmation dialog are always provided in the same order Both types of buttons are located on the right hand side. The left button always refers to going backwards or cancel the action, depending on the task performed. The right button corresponds to proceeding to the next step or confirming the task that is about to be performed.

\subsection{User Feedback and Support}

To increase the usability of OSN, the platform includes several features that help the users. On the main page, the user finds information about which feature or function can be found in which menu. Users who have more experience in using OSN may not need this kind of help; they do not have to read the introduction. But less experienced users this way do not have to use the 'trial and error' method to find the functions they are looking for; they can read the introduction to get to know the functionality and structure of the network.

Help-buttons are provided for the user when creating the personal profile. The user can click on the question marks in step 2 of creating a new profile and when adjusting the privacy settings.

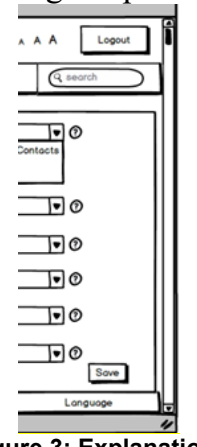

Figure 3: Explanation of privacy settings

In case of creating a profile, these buttons explain why the user should provide a particular information when creating a profile. When adjusting the privacy settings, the user gets more information about the impact of his decision. In this case, the function provides more detailed information about which users can see which data about the user.

All important actions the user wants to perform have to be confirmed by the user. Examples are: blocking or deleting a contact, leaving a group, booking a service, and paying for a service. Confirmation dialogs are implemented for that purpose. Another feature that helps users by giving them feedback are notifications, which inform about the successful completion of a task.

Since especially elderly users are concerned about the privacy of their data, the network provides a simple solution for editing the personal settings. These are divided into two groups: the general and the privacy settings. Under the category 'General Settings', the user can edit the general settings of his profile like user name, email address, and password. Afterwards it is possible to save the changes and the user receives a notification informing him all changes have been saved. Some information collected on a profile is private and is not supposed be seen by all users. This is also true for a user who does not want his profile picture seen by everyone or receive messages from users he does not know. The privacy settings can be set when creating the profile or later at any time. They could be accessed via the menu items 'Privacy Settings' and 'Change Privacy Settings'or by pressing the button 'Change Privacy Settings', as illustrated in Figure 4.

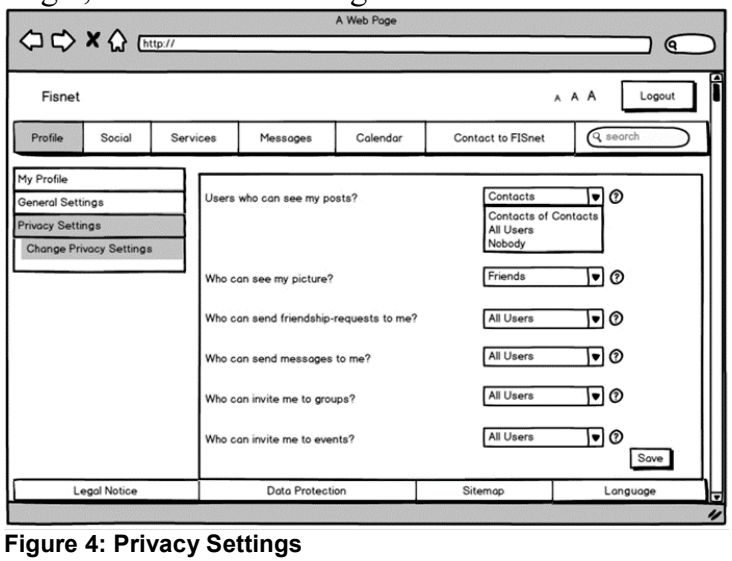

After editing all necessary information, the user can save the changes. The help buttons (questionmarks) next to the select boxes provide a possibility to get further information about the different possibilities of the privacy settings. The user receives an explanation about which effect the change of this individual privacy setting has on the visibility of his or her profile and postings. 


\subsection{Fonts}

Due to reduced eyesight of elderly users the font size should be large enough to be well readable but not too large, which would lead to more scrolling. To provide a font size that suits the requirements of all users, the user is able to adjust the font size to his or her eyesight and personal preferences. The user can choose between three different font sizes. The medium-sized font is used as the default setting; in this way, the user can choose between a smaller and a bigger font.

\section{Evaluation}

The qualitative empirical evaluation of the usability of the proposed UI design elements was carried out using a cognitive walkthrough. This method requires the participants of the study to perform through a series of tasks or questions. It allows to analyze the system's learnability for users from a certain target group and to evaluate problems that might occur when using a system. Lewis et al [32] state that cognitive walkthroughs are a good evaluation method in the early phase of the development process as in the present case. Compared to other empirical evaluation methods, the walkthrough only requires limited resources and can detect important problems encountered by the users of the design.

Here, the designed wireframes formed the basis for the walkthrough. Due to the fact that this was the first evaluation of the design, the tests were carried out using a "paper prototype" consisting of printed out wireframe drafts of the UI. To ensure the participants' focus on the structure and content of the UI instead off its visual design, all wireframes were kept abstract in black and white. Color and font design schemes were tested separately by a variant test. All tests were carried our using paper printouts, with the participants "clicking" on items by pointing at them with their fingers.

Before the test, the test participants did know nothing about the project and the planned OSN application.. Its objectives, functionalities, and the basic structure were explained to them right before the test started. Thus, all test persons had the same level of information in the beginning. In addition, the process of the test was explained to the test persons so that they knew what was expected of them, like i.e. that they had to verbalize all the actions they performed on paper.

During the test the participants got 36 tasks to perform with the application prototype. The list of tasks followed the structure of the OSN and included all possible tasks that could be performed. The tasks were read out loud to the participants and they could always ask in case they did not get the task right.

Before the test, all participants had the same level of information and did know anything about the project and the planned OSN application. Its objectives, functionalities, and the basic structure were explained to them directly before the test started. In addition, the process of the test was explained to the participants so that they knew what was expected of them, e.g. that they had to verbalize ("speak out loud") all the actions they performed on paper. The participants got 36 tasks to perform with the application prototype. The list of tasks followed the structure of the planned OSN and included all tasks that could be performed in the prototype, like:

- Creating a Profile

- Contacting another User

- Find and Order Services

- Evaluate Services

and others. These tasks were read out loud to the participants and they could always ask in case they did not get the task right.

During the test, the participants had the current wireframe in paper form in front of them. Each time a user pressed a button or entered text and a new UI screen should appear, a new wireframe replaced the old one. The test participant had to navigate through the application by choosing menu items and pressing buttons. All the time during these tasks, they should comment on their actions. This made it possible to reproduce their actions and analyze where problems occurred.

Afterwards, different design schemes for fonts and colors were shown to the participants to find out the preferred combinations (variant test).

These test sessions were audio-recorded and the recorded test protocols were transcribed. The written version was coded using the structure and the main functionalities of the network. In this way it is possible to assign each statement to a part of the network platform.

The evaluation was carried out in early 2016 with five different participants. All participants belong to the targeted age group between 55 and 75 and were generally capable of using online services on stationary devices, some of them even on mobile devices. Because German was the mother tongue of all participants, the tests were carried out in German language. The quotes cited in this paper therefore were translated into English by the authors (with the original German quote given in brackets).

The participants were anonymized by using the letter B (for "Befragter" / interviewee) and a number (1-5 in the order of the tests). A short overview of the five participants and their prior experience is shown in Table 1. 
Table 1: Overview of the participants

\begin{tabular}{|l|l|l|l|}
\hline Participant & Age & Gender & Online Experience \\
\hline B1 & 65 & Male & Much \\
\hline B2 & 59 & Female & Intermediate \\
\hline B3 & 59 & Female & Few \\
\hline B4 & 73 & Female & Intermediate \\
\hline B5 & 55 & Female & Much \\
\hline
\end{tabular}

\section{Results}

\subsection{Identified Problems}

Different types of problems with UI designs were identified during the evaluation. Table 2 summarizes these including their analysis by the authors.

Table 2: UI design problems identified during the evaluation

\begin{tabular}{|c|c|c|}
\hline Problem & Participants' Feedback & $\begin{array}{l}\text { Problem } \\
\text { Analysis }\end{array}$ \\
\hline Readability & $\begin{array}{l}\text { - About register tabs: } \\
\text { "The problem is that it } \\
\text { is not possible to } \\
\text { conclude this } \\
\text { ['News'] from this } \\
\text { ['Members']" (Das } \\
\text { Problem ist, dass } \\
\text { daraus nicht darauf zu } \\
\text { schließen ist (..), finde } \\
\text { ich.) (B1) } \\
\text { - About secondary } \\
\text { navigation bar: } \\
\text { "Well, I have to go } \\
\text { backward 'Edit } \\
\text { Profile'. Yes, I need to } \\
\text { go back to the start." } \\
\text { (Also auch wieder } \\
\text { ganz zurück. 'Profil } \\
\text { bearbeiten' Ja, ich } \\
\text { muss hier wieder ganz } \\
\text { zurück in das.) (B3) }\end{array}$ & $\begin{array}{l}\text { Users did not } \\
\text { look at all } \\
\text { available } \\
\text { submenu items. } \\
\text { But without the } \\
\text { tabs, the pages } \\
\text { would have } \\
\text { been too long } \\
\text { and the users } \\
\text { would have } \\
\text { needed to scroll } \\
\text { more. } \\
\text { Needs to be } \\
\text { tested again } \\
\text { with a software- } \\
\text { based click } \\
\text { model using } \\
\text { colored } \\
\text { highlighting to } \\
\text { indicate the } \\
\text { menu items the } \\
\text { user has } \\
\text { currently } \\
\text { chosen. }\end{array}$ \\
\hline $\begin{array}{l}\text { Understandi } \\
\text { ng Action } \\
\text { Items }\end{array}$ & $\begin{array}{l}\text { "Now I click here and } \\
\text { can click on the little } \\
\text { stars or do I have to } \\
\text { write a text?" (Und } \\
\text { jetzt drücke ich hier, } \\
\text { kann ich die Sternchen } \\
\text { anklicken oder muss } \\
\text { ich einen Text } \\
\text { schreiben?) (B2) }\end{array}$ & $\begin{array}{l}\text { Provide a more } \\
\text { detailed } \\
\text { explanation of } \\
\text { how the action } \\
\text { can be per- } \\
\text { formed and why } \\
\text { they have } \\
\text { certain rights. } \\
\text { Could be done } \\
\text { on the general }\end{array}$ \\
\hline
\end{tabular}

\begin{tabular}{|c|c|c|}
\hline & $\begin{array}{l}\text { - "I can delete him as a } \\
\text { member?" (Ich kann } \\
\text { ihn als Mitglied } \\
\text { löschen?) (B5). }\end{array}$ & $\begin{array}{l}\text { pages that } \\
\text { already exist for } \\
\text { some menu } \\
\text { items }\end{array}$ \\
\hline $\begin{array}{l}\text { Identifying } \\
\text { Buttons }\end{array}$ & $\begin{array}{l}\text { - "Oh no, not like that, } \\
\text { 'Change Privacy } \\
\text { Settings'. Now I can, } \\
\text { well, now I do not } \\
\text { want 'All Users' ..." } \\
\text { (Nee, so nicht. } \\
\text { 'Change Privacy } \\
\text { Settings'. Ah ja, jetzt } \\
\text { kann ich eben } \\
\text { entsprechend, also } \\
\text { jetzt will ich nicht } \\
\text { mehr 'All Users'...) } \\
\text { (B2) } \\
\text { - "Maybe I did not } \\
\text { notice it because it is } \\
\text { so far down in the } \\
\text { corner.") (Vielleicht } \\
\text { bin ich nicht darauf } \\
\text { gekommen, weil das } \\
\text { unten so in der Ecke } \\
\text { ist.) (B5) }\end{array}$ & $\begin{array}{l}\text { Position of } \\
\text { buttons has to } \\
\text { be recon- } \\
\text { sidered and } \\
\text { tested again } \\
\text { after changing } \\
\text { the position of } \\
\text { some buttons. }\end{array}$ \\
\hline $\begin{array}{l}\text { Screens } \\
\text { behind } \\
\text { opened } \\
\text { dialog boxes }\end{array}$ & $\begin{array}{l}\text { - “... I just choose } \\
\text { friends and click } \\
\text { 'Save'. Then I can see } \\
\text { again what has been } \\
\text { changed and click } \\
\text { 'Save' again.” } \\
\text { (...wähle jetzt nur } \\
\text { noch Freunde aus und } \\
\text { dann drücken ich } \\
\text { 'Save'. Dann kann ich } \\
\text { wieder sehen, dass das } \\
\text { geändert wurde und } \\
\text { dann kann ich auf } \\
\text { 'Save' drücken.) (B2) }\end{array}$ & $\begin{array}{l}\text { Screens that lie } \\
\text { behind dialog } \\
\text { boxes need to } \\
\text { be revised } \\
\text { completely. }\end{array}$ \\
\hline
\end{tabular}

There are a number of other problems that require a revision of the wireframes. For instance, the notifications for the administrator who excluded users from groups have to be revised. Another revision to be made has to do with the splitting of general and privacy settings because it caused some confusion among all test persons.

\subsection{Positive Findings}

The positive aspects of the UI design identified in the evaluation are summarized in table 3 . 
Table 3: Positive aspects about the UI design identified during the evaluation

\begin{tabular}{|c|c|c|}
\hline UI Element & Participants' Feedback & Analysis \\
\hline $\begin{array}{l}\text { Password } \\
\text { Guidelines } \\
\text { (clickable } \\
\text { during the } \\
\text { creation of a } \\
\text { user profile) }\end{array}$ & 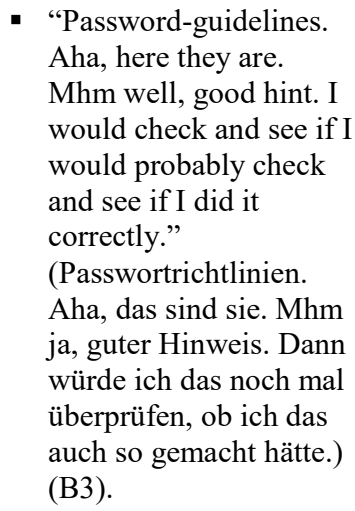 & \\
\hline $\begin{array}{l}\text { Privacy } \\
\text { settings }\end{array}$ & $\begin{array}{l}\text { - } \text { "Aha, who can see my } \\
\text { posts, well, that is great. } \\
\text { That you can limit it } \\
\text { here." (Aha, wer kann } \\
\text { meine Beiträge ansehen, } \\
\text { na das ist ja mal toll. } \\
\text { Dass man da gleich mal } \\
\text { eingrenzt.) (B3) } \\
\text { - Test person B5 also } \\
\text { mentioned that it was } \\
\text { useful to adapt the } \\
\text { privacy settings this } \\
\text { early: "This is fun." } \\
\text { (Das macht Spaß) (B5). }\end{array}$ & \\
\hline $\begin{array}{l}\text { Position-ing } \\
\text { of Buttons }\end{array}$ & $\begin{array}{l}\text { - "This one is positioned } \\
\text { well down there." (Der } \\
\text { ist auch gut angebracht } \\
\text { da unten.) (B3) }\end{array}$ & $\begin{array}{l}\text { Perception of } \\
\text { the positioning } \\
\text { of buttons } \\
\text { depends on } \\
\text { the user and } \\
\text { his personal } \\
\text { preferences. }\end{array}$ \\
\hline $\begin{array}{l}\text { Structure of } \\
\text { pages / } \\
\text { users' } \\
\text { guidance }\end{array}$ & $\begin{array}{l}\text { - "Here it becomes very } \\
\text { clear again. And now I } \\
\text { can click on them one } \\
\text { after another." (Aha, } \\
\text { jetzt wird es wieder } \\
\text { ganz eindeutig. Und } \\
\text { jetzt kann ich die } \\
\text { nacheinander anklicken) } \\
\text { (B4) } \\
\text { "Okay, 'Conditions', } \\
\text { 'Prices', 'Description', } \\
\text { 'Read Service } \\
\text { Evaluation', zag, up } \\
\text { here. Wonderful. Ah, } \\
\text { ok. It is like planning a }\end{array}$ & \\
\hline
\end{tabular}

\begin{tabular}{|c|c|c|}
\hline & $\begin{array}{l}\text { holiday. Good.” (Okay. } \\
\text { 'Konditionen', 'Preise', } \\
\text { 'Beschreibungen'. (..) } \\
\text { 'Servicebewertung } \\
\text { lesen', zack, hier oben. } \\
\text { Wunderbar. Ah, okay. } \\
\text { Wie bei der } \\
\text { Urlaubsplanung. Gut.) } \\
\text { (B3) } \\
\text { “Okay, this is all } \\
\text { prescribed, very good.” } \\
\text { (okay, das wird alles } \\
\text { vorgegeben, sehr gut.) } \\
\text { (B3) }\end{array}$ & \\
\hline $\begin{array}{l}\text { Constant } \\
\text { feedback } \\
\text { about } \\
\text { performed } \\
\text { actions }\end{array}$ & $\begin{array}{l}\text { - "The page tells me that } \\
\text { all these things have } \\
\text { been saved. Wonderful." } \\
\text { (Die Seite sagt mir jetzt, } \\
\text { dass all diese Dinge } \\
\text { gesichert sind. } \\
\text { Wunderbar." (B1) } \\
\text { - "Well, the confirmation } \\
\text { that you always see } \\
\text { what you have done, I } \\
\text { think it is very } \\
\text { important" (Also die } \\
\text { Bestätigung, dass man } \\
\text { das immer gleich } \\
\text { wiedersieht, was man } \\
\text { gemacht hat, das finde } \\
\text { ich ganz wichtig.) (B3) }\end{array}$ & $\begin{array}{l}\text { Constant } \\
\text { feedback is } \\
\text { important for } \\
\text { users to make } \\
\text { sure that their } \\
\text { actions have } \\
\text { been } \\
\text { performed as } \\
\text { desired. }\end{array}$ \\
\hline
\end{tabular}

\subsection{Fonts and Colors}

The preferable fonts and color schemes were evaluated using a variant test . Each participant was presented two variants (two different font types or two different color schemes) for one wireframe. He or she chosed the one he preferred based on better readability, personal taste or other arguments. The one the variant rejected was replaced by another variant. The test continued until only one variant remained. In this way, the participants chose his or her favorite font and color scheme.

All users decided that they did not like fonts with serifs. "No, those serifs, personally I do not like them. I think it is clearer in Verdana." (Nee, diese, diese Serifen da, die finde ich persönlich nicht so schön, ich finde es klarer bei Verdana.) (B5), "I am not a fan of serifs." (Ich bin kein Fan von Serifen.) (B5), "Ah yes, I think it is unnecessary." (Ach so ja, finde ich eigentlich überflüssig) (B3), "I would prefer a clear picture" (Ich würde so ein klares Bild vorziehen) (B3).

The participants did not agree on a favorite font. The five test persons chose four different font types. Two 
chose Tahoma: "I like Tahoma better because it looks a little bit bigger and is easier to decipher." (Ich mag Tahoma lieber, die wirkt ein bisschen größer, ich kann das irgendwie besser erkennen.) (B2). One test person chose Arial "I like Arial better." (Mir gefällt Arial besser.) (B1). Another participant opted for Calibri: "I simply think Calibri is nicer." (Ich finde Calibri einfach schöner), "I can tell without a doubt if the word is capitalized or uncapitalized." (hier kann ich ganz deutlich erkennen ob großes oder kleines Wort.) (B3). The last test person chose Verdana as her favorite font:"I think it is clearer with Verdana." (Ich finde es ist klarer bei Verdana.) (B5).

The conclusion for the interface is that a classical web-safe font without serifs is suitable for the target group. Readability is the most important factor; font size is another one, as one can see in the fact that two users decided for Tahoma because they perceived this font as bigger and therefore found it easier to read.

The majority of test persons preferred a beige background because of the better readability. "The beige background is significantly more comfortable." (Das beige ist wesentlich angenehmer.) (B2), "No, I think it is very comfortable." (Nein, ich finde das sogar sehr angenehm.) (B3), "Well, I never imagined it at all. This is really great. Well, ha, this is quite a new idea. (...) And if you look at it, this is a real eye-catcher, such an eyecatcher and, neverthe-less, the information still stands out." (Ja. Hätte ich jetzt gar nicht gedacht. Aber das ist wirklich toll. Gut, ha, das ist mal eine neue Idee. ... Und wenn man guckt, das ist so ein Hingucker, so ein eyecatcher und trotzdem kommt die Information noch gut raus.) (B3), “Anyway, I like it" (Doch, das gefällt mir) (B4), "The beige background, the white one is too harsh, it's too contras-tive." (Beiger Hintergrund. Das weiß ist zu hart, das ist sehr kontrastig.) (B5).

Regarding the colors, there is no clear favorite. Three test persons preferred the red scheme, one test person the cold-blue one, and the fifth test person the green one. The clearer colors were preferred by the test persons because they provided a good contrast. Color schemes with little contrast or too much contrast were not favored by the test persons. Female participants favored warm colors (with one exception), whereas the male chose the combination of two colder shades of blue.

\section{Modifications to the UI}

Based on the results of the evaluation, the proposed UI design was partially modified.

The possibility to adjust the font size was not noticed by the test persons at first. After searching for a while, they found the three As in the upper right part of the website to change the font size. To mark the function more clearly, a short explanation added as illustrated in Figure 5.

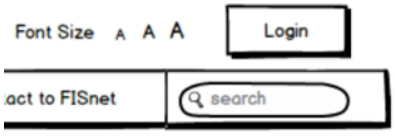

Figure 5: Revised version of the font size selection

The differentiation between general and privacy settings led to some confusion during the test. The users were not sure about which settings could be found in which category. As a reaction to this confusion, the division of the menu item 'Settings' has been changed. The content of the settings has remained the same. A menu item 'Settings' was introduced and the account settings and privacy settings are now part of the overall category "Settings". The sub menu 'Settings' explains which settings can be found where, and how the user can adapt the settings. The category 'Account Settings' now contains the settings that used to be part of the 'General Settings' before.

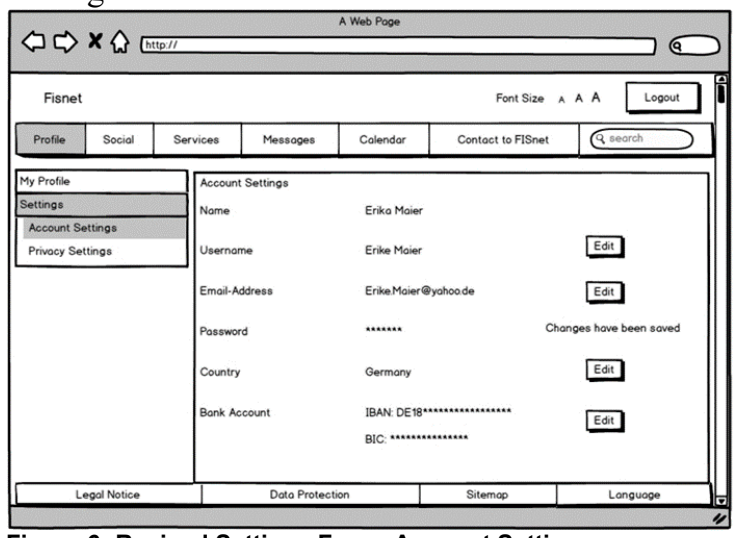

Figure 6: Revised Settings Form: Account Settings

Changing the name from 'General Settings' to 'Account Settings' should make it easier for the users to find the settings they want to edit. The way to edit the account settings has remained the same because no further problems with changing these settings occurred during the tests.

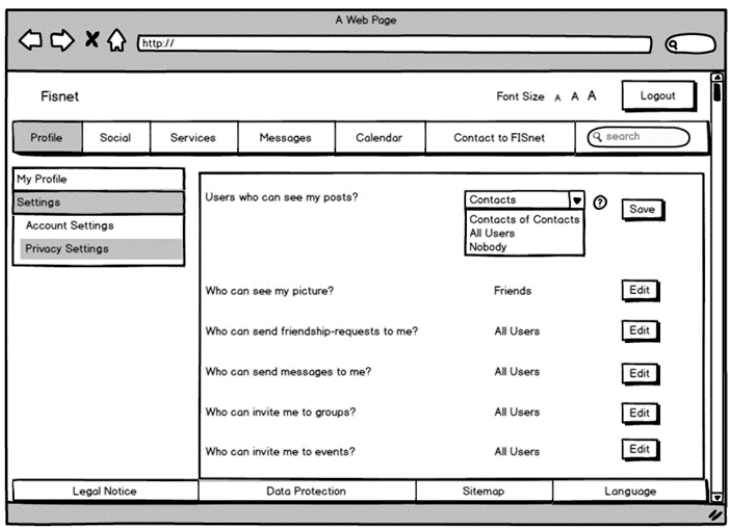

Figure 7: Reworked Settings: Account Settings 
The content of the privacy settings has not been changed. Due to the fact that some test persons had problems finding the button 'Change Setting' to edit the privacy settings, the process of editing the privacy settings has been changed. In analogy with the account settings, the user can click on the button 'Edit' next to every setting. After clicking on the button, the drop down selection appears and the user can choose between the options 'Contacts', 'Contacts of Contacts', 'All Users', and 'Nobody', just like before. The button 'Change Settings' has disappeared because it is not needed anymore. Thus, the process of editing is the same for both types of settings and the user only has to learn one method.

Despite most of the modifications were related to settings, further changes were made by adding more comprehensive, context-related explanations regarding blocking and deleting contacts, deleting group members and service details. In general, the evaluation revealed that the participants required more online information and help on the possible consequences of their settings or actions performed throughout the UI.

\section{Limitations and Further Research}

The main limitation of the present study is that only a low-fidelity, paper-based prototype consisting of wireframes has been evaluated. Some results made may be artifacts due to the lack of interactivity and a realistic look-and-feel. In addition, only a relatively small number of participants (5) took part in the empirical study.

\section{References}

[1] O. Pötzsch and F. Rößger, "Bevölkerung Deutschlands bis 2060 - 13. koordinierte Bevölkerungsvorausberechnung," Statistisches Bundesamt, Wiesbaden 2015.

[2] S. Goswami, F. Köbler, J. M. Leimeister, and H. Krcmar, "Using Onlien Social Networking to Enhance Social Connectedness and Social Support for the Elderly," in Proceedings of the 31th International Conference on Information Systems, St Louis, Missouri, USA, 2010.

[3] G. Craig, "Citizenship, Exclusion and Older People," Journal of Social Policy, vol. 33, pp. 95 114, 2004.

[4] B. E. N. Heaven, Brown, L. J., White, M., Errington, L., Mathers, J. C., \& Moffatt, S., "Supporting Well-Being in Retirement through Meaningful Social Roles: Systematic Review of Intervention Studies," Milbank Quarterly, vol. 91, pp. 222-287, 2013.

[5] A. E. Stuck, J. M. Walthert, T. Nikolaus, C. J. Bula, C. Hohmann, and J. C. Beck, "Risk factors for functional status decline in community-living elderly people: a systematic literature review,"
In addition, the diversity of the participants with respect to their age, gender, education and regional/

cultural background was strongly limited due to the small number (5). This might lead to an inherent bias in the evaluation results, which needs to be further investigated.

Therefore, the study will be extended in a next step using a software-based prototype and including more (and more diverse) participants.

\section{Conclusion}

In conclusion, in the present paper a design approach for typical structural elements of UI for a OSN specific

for users in the transition age (55-75 years of age) was presented.

The proposed UI design was evaluated by a qualitative empirical study using a cognitive walkthrough. The participants of the study all were selected from the target group of transition agers (55-75 years of age).

Despite the limited number of participants taking part in the study, the results already indicate that with specific but limited adjustments of typical UI elements, OSN could be made better suitable for people in the transition age.

This research received funding from the German Federal Ministry of Education and Research (BMB"F) under grant code 01FR14021. The responsibility for the content of this publication lies with the authors.

Social Science \& Medicine, vol. 48, pp. 445-69, Feb 1999.

[6] W. Keijzer-Broers, L. F. Nikayin, M. de Reuver, "Main requirements of a Health and Wellbeing Platform: findings from four focus group discussions," in Proceedings of the 25th Australasian Conference on Information Systems, Auckland, New Zealand, 2014.

[7] D. Harley, K. Howland, E. Harris, and C. Redlich, "Online communities for older users: what can we learn from community interaction to create social sites that work for older people," in Proceedings of the 28th International BCS Human Computer Interaction Conference, Southport, UK, 2014, pp. 42-51.

[8] Statista. (2014, November 11). Altersverteilung der Nutzer von ausgewählten sozialen Netzwerken weltweit im 3. Quartal 2014 http://de.statista.com/statistik/daten/studie/40800 6/umfrage/altersverteilung-der-nutzer-vonsocial-networks-nach-plattform/.

[9] H. Pensas, T. Kivimäki, A.-M. Vainio, S. Konakas, S. Costicoglou, P. Kölndorfer, et al., "Building a Client-Server Social Network 
Application for Elders and Safety Net," in Proceedings of International Conference on Making Sense of Converging Media, Tampere, Finland, 2013, pp. 310-312.

[10] D. Hawthorn, "How Universal is Good Design for Older Users?," in Proceedings of the 2003 conference on Universal usability, Vancouver, British Columbia, Canada, 2003, pp. 38-45.

[11] C. Leonardi, A. Albertini, F. Pianesi, and M. Zancanaro, "An Exploratory Study of a Touchbased Gestural Interface for Elderly," in Proceedings of the 6th Nordic Conference on Human-Computer Interaction: Extending Boundaries, Reykjavik, Iceland, 2010, pp. 845850.

[12] F. Boll and P. Brune, "User Interfaces with a Touch of Grey? - Towards a Specific UI Design for People in the Transition Age," presented at the The 5th International Conference on Current and Future Trends of Information and Communication Technologies in Healthcare (ICTH 2015) Berlin, Germany, 2015.

[13] N. H. Anderson, "Foundations of Information Integration Theory," The American Journal of Psychology, vol. 95, pp. 708-711, 1982.

[14] B. N. Schenkman and F. U. Jönsson, "Aesthetics and Preferences of Web Pages," Behaviour \& Information Technology, vol. 19, pp. 367-377, 2000/01/01 2000.

[15] K. Karvonen, "The Beauty of Simplicity," in Proceedings on the 2000 conference on Universal Usability, Arlington, Virginia, USA, 2000, pp. 8590.

[16] A. Basso, D. Goldberg, S. Greenspan, and D. Weimer, "First Impressions: Emotional and Cognitive Factors Underlying Judgments of Trust E-Commerce," in Proceedings of the 3rd ACM Conference on Electronic Commerce, Tampa, Florida, USA, 2001, pp. 137-143.

[17] G. Lindgaard and C. Dudek, "User Satisfaction, Aesthetics and Usability: Beyond Reductionism," in Proceedings of the IFIP 17th World Computer Congress - TC13 Stream on Usability: Gaining a Competitive Edge, 2002, pp. 231-246.

[18] J. Häikiö, A. Wallin, M. Isomursu, H. Ailisto, T. Matinmikko, and T. Huomo, "Touch-based user interface for elderly users," in Proceedings of the 9th International Conference on Human Computer interaction with Mobile Devices and Services, Singapore, 2007, pp. 289-296.

[19] M. Leitner, Ö. Subasi, N. Höller, A. Geven, and M. Tscheligi, "User requirement analysis for a railway ticketing portal with emphasis on semantic accessibility for older users," in Proceedings of the 2009 International CrossDisciplinary Conference on Web Accessibililty (W4A), Madrid, Spain, 2009, pp. 114-122.

[20] P. G. Fairweather, "How Older and Younger Adults Differ in their Approach to Problem Solving on a Complex Website," in Proceedings of the 10th international ACM SIGACCESS
Conference on Computers and Accessibility, Halifax, Nova Scotia, Canada, 2008, pp. 67-72.

[21] P. Gregor, A. F. Newell, and M. Zajicek, "Designing for Dynamic Diversity: interfaces for older people," in Proceedings of the 5th International ACM conference on Assistive Technologies, Edinburgh, Scotland, 2002, pp. 151-156.

[22] S. Sayago and J. Blat, "About the Relevance of Accessibility Barriers in the Everyday Interactions of Older People with the Web," in Proceedings of the 13th International Cross-Disciplinary Conference on Web Accessibililty, Madrid, Spain, 2009, pp. 104-113.

[23] A. L. Dias, R. P. d. M. Fortes, P. C. Masiero, W. M. Watanabe, and M. E. Ramos, "An Approach to Improve the Accessibility and Usability of Existing Web System," in Proceedings of the 31st ACM International Conference on Design of Communication, Greenville, North Carolina, USA, 2013, pp. 39-48.

[24] N. Musa, S. N. Junaini, and Y. R. Bujang, "Improving Usability of E-recruitment Website: A Preliminary Study on Sarawak Government Website " in Proceedings of the 10th Pacific Asia Conference on Information Systems, Kuala Lumpur, Malaysia, 2006, pp. 507-515.

[25] P. Zaphiris, M. Ghiawadwala, and S. Mughal, "Age-Centered Research-Based Web Design Guidelines," in Proceedings of the 2005 Conference on Human Factors in Computing Systems, Portland, OR, USA, 2005, pp. 18971900.

[26] T. Kivimäki, P. Kölndorfer, A.-M. Vainio, H. Pensas, T. Vuorela, M. Garschall, et al., "User Interface for Social Networking Application for the Elderly," in Proceedings of the 6th International Conference on Pervasive Technologies Related to Assistive Environments, Rhodes, Greece, 2013, pp. 1-8.

[27] W. Keijzer-Broers. L. Florez-Atehortua. M. de Reuver, "Prototyping a Health and Wellbeing Platform: an Action Design Research Approach," in 49th Hawaii International Conference on System Sciences (HICSS), Koloa, Hawaii, USA, 2016, pp. 3462-3471.

[28] J. Nielsen. (2006, February 11, 2016). F-Shaped Pattern For Reading Web Content.

[29] C. C. E. Malone, Designing Social Interfaces vol. 1. Sebastopol, CA: O'Reilly Media Inc., 2009.

[30] V. Friedman, Praxisbuch Web 2.0. Bonn: Galileo Press, 2009.

[31] B. Rohles, Grundkurs Gutes Webdesign. Bonn: Galileo Press, 2013.

[32] C. Lewis, P. G. Polson, C. Wharton, and J. Rieman, "Testing a Walkthrough Methodology for Theory-Based Design of Walk-Up-and-Use Interfaces," in Proceedings of the SIGCHI Conference on Human Factors in Computing Systems, Seattle, Washington, USA, 1990, pp. 235-242. 